\title{
DO DIREITO DE USAR AO DIREITO DE FAZER: O CASO MONSANTO E O CONFLITO ENTRE O USO E O ABUSO DO DIREITO À PATENTE
}

\section{FROM THE RIGHT TO USE TO THE RIGHT TO DO: MONSANTO CASE STUDY AND THE CONFLICT BETWEEN USE AND ABUSE IN PATENT RIGHTS}

\author{
${ }^{1}$ Leônidas Meireles Mansur Muniz de Oliveira \\ ${ }^{2}$ Jorge Mascarenhas Lasmar
}

\section{RESUMO}

O presente trabalho tem como objetivo apresentar uma reflexão sobre a interface existente entre o uso e o abuso do direito à patente. Para alcançar o objetivo proposto será utilizado o método bibliográfico com enfoque no caso concreto envolvendo a disputa judicial contra a empresa Monsanto. Sendo assim, foi analisada uma vasta doutrina sobre o tema buscando identificar no caso concreto qual é a interface que equilibra o direito à patente. Os direitos de propriedade intelectual recorrentemente ocupam as páginas dos mais importantes jornais do mundo, demonstrando os conflitos existentes entre os mais diversos países quando o assunto se faz o uso exclusivo de determinado invento. É nesse ponto que pousa a relevância da pesquisa sobre o tema, vez que os direitos de propriedade intelectual necessitam de reflexões acadêmicas sobre os conflitos que os circundam.

Palavras-chave: Propriedade intelectual, Patentes, Caso monsanto

\begin{abstract}
This study aims to present a reflection on the interface between the use and abuse of the right to patent. Bibliographic method will be developed to achieve the proposed objective focusing on the specific case involving the legal battle against the company Monsanto. Thus, a vast literature was analyzed on the subject trying to identify in this case what is the interface that balances the right to the patent. Intellectual property rights repeatedly occupy the pages of the major newspapers in the world, demonstrating the existing fight between the most diverse countries when it becomes the exclusive use of a particular invention. This is where the relevance of this research on the subject lays, once the intellectual property rights require academic reflections on the conflicts surrounding intellectual property.
\end{abstract}

Keywords: Intelectual property, Patents, Monsanto case study

\footnotetext{
${ }^{1}$ Mestre em Mestrado em Direito Empresarial pela Faculdades Milton Campos - FMC, Minas Gerais,MG, (Brasil). Coordenador do Setor Trabalhista e Empresari no escritório Tomáz de Aquino, Costa Vilar Sociedade de Advogados, TACV. E-mail: leonidasmansur@yahoo.com.br.

${ }^{2}$ Doutor em Relações Internacionais pela London School of Economics and Political Sciences - LSE, Londres, Inglaterra. Coordenador da Graduação na Pontifícia Universidade Católica de Minas Gerais - PUC Minas, Minas Gerais. (Brasil). E-mail: jorgelasmar@gmail.com.
} 


\section{INTRODUÇÃO}

A propriedade intelectual faz parte de um rol de direitos internacionalmente reconhecidos. O caráter internacional desse ramo do direito confere ao mesmo uma grande importância no que tange sua execução e principalmente sua observação. Constantemente os direitos da propriedade intelectual são o cerne de grandes discussões internacionais, vez que países disputam entre si a medida certa de como aplicar tais direitos.

O Brasil faz-se palco de calorosas discussões que envolvem o direito de propriedade intelectual, como no caso do uso de medida compulsória em face dos medicamentos contra o HIV, algumas vezes é acusado de não observa-lós, outras, é ressaltado por honra-lós. Toda essa conotação nacional e internacional que pousa sobre os direitos da propriedade intelectual faz com que as discussões acerca do tema sejam sempre atuais e de extrema relevância. É que a força das grandes nações, na contemporaneidade, se mede por sua capacidade inventiva e tecnológica. Nesse ponto, o direito de propriedade intelectual tem um importante papel, vez que reconhece a exclusividade ao dono da ideia por meio do direito à patente.

A exclusividade concedida é conhecida como patente e traz com o seu reconhecimento uma série de direitos para o seu detentor e uma série de deveres para os que estão passíveis de sua imposição. Nesse diapasão, existe uma interface entre o uso e o abuso do direito à patente que deve ser identificada e discutida pela comunidade acadêmica. $\mathrm{O}$ famoso caso envolvendo a multinacional americana Monsanto traz exatamente a necessidade de se determinar concretamente qual é o linhame que separa o uso do abuso das patentes.

O presente trabalho foca no caso Monsanto para refletir sobre o assunto e demonstrar qual é a interface que compõe o direito à patente quando se pretende determinar o limite entre o uso e o abuso de tal direito. A disputa figurada no caso que será utilizado como objeto da pesquisa denota exatamente o antagonismo entre o direito de fazer e o direito de usar. Será que a justiça brasileira ao considerar contra a lei a cobrança de royalties pela Monsanto violou os direitos da propriedade intelectual ou apenas delimitou a interface entre o uso e abuso das patentes? É nas curvas deste questionamento que se funda o presente trabalho.

\section{PROPRIEDADE INTECTUAL E SUAS RAÍZES HISTÓRICAS}

A propriedade intelectual vem sendo discutida por diversos países ao longo dos anos, como por exemplo, Estados Unidos, Brasil, França, Alemanha, Portugal, dentre outros. ntre tratados e legislações internas tornou-se um ramo autônomo e de grandes implicações no direito internacional e no direito brasileiro. Com o primor da comercialização e do 
surgimento da concorrência no mercado internacional cresceu o interesse dos países em legitimar um mecanismo que tivesse o escopo de proteger tudo o que advinha do intelecto humano com o fito de desenvolver o comércio e a indústria, ou seja, invenções e inovações. Ocorre que o que motivou, também, o aprimoramento constante dos direitos da propriedade intelectual foram os direitos autorais, que durante o Século XIX chegou a ser utilizado como definição de propriedade intelectual.

Ao se abordar o tema é de suma importância ressaltar que os direitos da propriedade intelectual são compostos por dois grupos: os direitos autorais e a propriedade industrial. Essa bifurcação que se somada resulta no rol de direitos denominados de propriedade intelectual é assim condicionada exatamente por conta de seu desenrolar histórico. Para se delinear as raízes históricas de tal ramo do direito é preciso criar um divisor de águas entre o Século XIX e o Século XX, chegando por fim aos contornos contemporâneos.

Tal divisor entre os Séculos XIX e XX se faz de crucial importância para se atribuir, na contemporaneidade, conceito certo aos direitos da propriedade intelectual. É o que pode se extrair do trecho abaixo:

A Convenção da OMPI define como Propriedade Intelectual, a soma dos direitos relativos às obras literárias, artísticas e científicas, às interpretações dos artistas radiodifusão, às invenções em todos os domínios da atividade humana, às descobertas científicas, aos desenhos e modelos industriais, às marcas industriais, comerciais e de serviço, bem como às firmas comerciais e denominações comerciais, à proteção contra a concorrência desleal e todos os outros direitos inerentes à atividade intelectual nos domínios industrial, científico, literário e artístico.

Antes da definição convencional, a expressão "Propriedade intelectual" aplicava-se, mais restritamente, aos direitos autorais; nesta acepção, encontramos extenso emprego na doutrina anterior. Em sua origem, porém, como concebido por Josef Kohler e Edmond Picard nos fins do Sec. XIX, o conceito correspondia ao expresso na Convenção da OMPI. (BARBOSA, 2015, pg. 07)

Da lição apresentada, percebe-se o quanto se faz importante o delinear histórico da propriedade intelectual para que se possa compreender o seu conceito e seus componentes. Sendo assim, ao se tratar de tal delinear temporal a doutrina estabelece como marco principal as Convenções de Berna e Paris.

As Convenções de Berna e de Paris foram criadas no Século XIX com o intuito de amenizar os conflitos multilaterais que surgiam entre as mais diversas nações. A diferença 
entre elas é que a Convenção de Berna foi criada com o escopo de regular os direitos autorais, enquanto que a Convenção de Paris possuía o intuito de regular a propriedade industrial. Esta foi criada em 1883 e teve como países participantes países como Itália, Holanda, Portugal, Espanha, França, Bélgica, Suíça, Reino Unido, Tunísia e Brasil. O objetivo primordial da Convenção de Paris foi estabelecer princípios que regulassem a propriedade intelectual. Tais princípios atuam como iluminadores dos direitos da propriedade intelectual e podem ser decantados em quatro princípios, são eles: tratamento nacional, prioridade unicionista, interdependência de direitos, territorialidade.

O princípio do tratamento nacional pode ser traduzido como a busca de tratamento nacional no que tange direitos, deveres e proteção de produtos quando o mesmo for de origem de um dos países componentes da convenção. O princípio da prioridade unicionista é aquele que versa sobre o pedido de depósito de patentes, ou seja, o primeiro pedido de depósito de uma patente realizado em um dos países membros, desde que observe algumas condições, servirá de base para pedidos de depósitos de patente nos outros países membros. Já o princípio da interdependência de direitos ensina que o depósito ou patente reconhecidos em um dos países membros são completamente independentes de seus correspondentes em outros países, sendo estes membros ou não da convenção. Por fim, tem-se o princípio da territorialidade que pode ser traduzido como a circunscrição territorial de validade de um direito de propriedade intelectual, ou seja, um direito de propriedade intelectual concedido só será válido nos limites territoriais do país concedente.

A Convenção de Berna criada em 1886 contou com a união de países como Espanha, Suíça, França, Tunísia, Bélgica, Reino Unido, Alemanha e Itália. A referida convenção foi uma preocupação expressa dos países europeus sobre a proteção dos direitos de seus autores. Tanto que países como Brasil e Estados Unidos da América só vieram a aderir a tal convenção tardiamente. A Convenção de Berna expressou alguns princípios todos voltados á proteção de direitos autorais e ficou marcada por elencar dois patamares distintos da proteção aos direitos autorais: proteção patrimonial e proteção moral.

Alguns anos depois a União de Paris e Berna se fundiram com o fito de abranger os seus principais ideias, na seguinte denominação:

Em 1983, a CUB e a CUP unificaram a administração dos tratados em um único escritório, o Escritório Internacional Unificado pela Proteção da Propriedade Intelectual (BIRPI), com sede em Berna até 1960. O Escritório foi financiado e gerido pelo governo suíço até a criação da OMPI. Em 1898, o BIRPI administrava, além do CUB e CUP, outros dois tratados: o Tratado de Madri, relativo ao Registro 
Internacional de Marcas, e o Acordo de Madri para a repressão de Indicação de Origem Falsa ou Enganosa, ambos de 1891. (SOUZA, 2009, pg. 43-44)

Como se percebe a primeira fase da história do direito de propriedade intelectual foi marcada por duas principais convenções com objetivos de proteção completamente distintos, motivo pelo qual o Século XIX possuiu uma divisão doutrinaria acerca da definição de diretos da propriedade intelectual. Contudo percebe-se que essa primeira fase foi encerrada com a união dos objetivos de proteção das Convenções de Paris e Berna o que impulsionou uma definição mais abrangente de propriedade intelectual e deu um impulso para abertura da segunda fase histórica marcada pela criação da Organização Mundial da Propriedade Intelectual.

A criação da Organização Mundial da Propriedade Intelectual (OMPI) se faz o marco inicial da propriedade intelectual do Século XX justamente por ser banhada pelo crescente desenvolvimento tecnológico e a comercialização internacional. A concretização de países desenvolvidos e países em desenvolvimento criou uma robusta corrida em prol de tecnologia para se efetivar os meios de produção e a possibilidade de participação no mercado internacional e no desenvolvimento interno de cada país. A OMPI surge no contexto de mediar à disputa existente entre países desenvolvidos e países em desenvolvimento na busca pela efetivação de suas respectivas economias.

A instituição da OMPI possui marcos temporais diferentes, vez que sua criação institucional e a grande aderência ocorreram em anos diferentes. Pode se afirmar que a convenção que deu marco à OMPI foi datada de 1967 e que sua maior aderência ocorreu por volta dos anos 2000 e 2007. Os objetivos da OMPI tiveram como divisor de águas à sua aderência a Organização das Nações Unidas, pois seus objetivos inicias eram basicamente propiciar a proteção da propriedade intelectual. Com à aderência a ONU a Convenção teve que se adequar aos objetivos principais trazidos pela Organização das Nações Unidas em 1970.

A aderência da OMPI à ONU alargou seus objetivos, vez que passou a se responsabilizar por todos os acordos e tratados feitos sobre sua responsabilidade. A essência da OMPI foi além de proteger o desenvolvimento da propriedade intelectual, se transformouem uma responsabilidade tal proteção em face de todos os Estados partes. Sobre as características da OMPI se faz de suma importância a lição seguinte:

No preâmbulo, o documento manifesta o desejo das partes contratantes de contribuir para uma melhor compreensão e colaboração entre estados, para seu benefício 
mútuo, respeitadas sua soberania e igualdade; expressa se tal desejo " a fim de estimular a atividade criativa, promover em todo o mundo a proteção da propriedade intelectual" (OMPI, 1970). Claramente, o objetivo é promover a proteção a um conjunto de regras e não à inovação, à criatividade e ao desenvolvimento econômico, os quais funcionam como variáveis dependentes da eficiência dessa proteção. Esse pressuposto será radicalizado na criação da OMC.

A Convenção possui 21 artigos sobre os aspectos gerais da organização, cujas finalidades são explicitas no Art. 3: i) "promover a proteção da propriedade intelectual em todo o mundo, pela cooperação dos Estados, em colaboração, se for caso disso, com qualquer outra organização internacional"; e ii) "assegurar a cooperação administrativa entre as Uniões".

Até os anos 1970 , a OMPI mantém o mesmo objetivo e pretensão à universalidade do BIRP; a partir deste ano, quando é incorporada às Nações Unidas, a OMPI precisa, pelo menos formalmente, adaptar seus objetivos com as metas mais gerais da ONU. Através de um Acordo de 1971, a ONU reconhece a OMPI como organização especializada, responsável por garantir a aplicação e a eficácia dos tratados e acordos por ela administrados, visando a promover a atividade intelectual criativa e a facilitar a transferência de tecnologia aos países em desenvolvimento, de forma a acelerar seu desenvolvimento econômico, social e cultural. A incorporação inclui a representação recíproca nas sessões, com o direito a participar das deliberações, bem como o direito de incluir recomendações e temas nas agendas, trocas de informações e documentos, assistência técnica e transferência de tecnologia entre as organizações. Apenas o direito a voto está excluído. (SOUZA, 2009, pg. 45-46)

Assim como no cenário internacional, o Brasil, também, é composto por diversos momentos que denotam a evolução histórica dos direitos da propriedade nacional. $\mathrm{O}$ autor Denis Borges Barbosa traz em sua obra Tratado da Propriedade Intelectual diversos momentos que demonstram a evolução histórica do direito da propriedade intelectual no Brasil. O autor afirma que o Brasil foi um dos pioneiros ao redor do mundo em direitos da propriedade intelectual desde a época do Império:

No primeiro ato do Príncipe Regente - a Abertura dos Portos -, tão festejado pelos livros de História escolar, abolem-se as vedações absolutas de acesso ao mercado rasileiro, característica do regime colonial, impondo-se uma tarifa geral de $24 \%$ às mercadorias estrangeiras. [...]

Nesse contexto, temos uma lei de patentes desde 28 de abril de 1809, um Alvará de D. João VI aplicável somente ao Estado do Brasil, o que nos coloca como uma das quatro primeiras nações, no mundo, a ter uma legislação sobre o tema. Tal Alvará Régio foi possivelmente também o nosso primeiro Plano de Desenvolvimento Econômico. (BARBOSA, 2015, pg. 12) 
Como se percebe, no trecho citado, desde 1809 o Brasil já manifestava sua preocupação em regulamentar o direito da propriedade intelectual. Ocorre, que tal preocupação no decorre dos anos sempre foi voltada às invenções e inovações, sendo pouco explorada a proteção dos direitos autorais, marcas e nome empresarial. Com as mudanças políticas ocorridas no Brasil, que foram diversas, ocorria a substancial mudança na legislação que regulava os direitos da propriedade intelectual.

Percebe-se que o Brasil sempre se preocupou em regular e bem determinar os direitos da propriedade intelectual como uma forma de se integrar ao mercado e garantir seu desenvolvimento econômico acompanhado as transformações mundiais. Denis Borges Barbosa (2015, pg. 17) afirma que o Brasil teve "um série de leis extravagantes" que tentaram regular da melhor forma possível as mais diversas matérias que envolvem os direitos da propriedade intelectual.

No ano de 1996 em meio a forte pressão dos Estados Unidos da América e das negociações multilaterais o Brasil publicou a Lei 9.729 que passou a regular as mais diversas questões sobre propriedade intelectual, marcas, patentes, inovação, invenção e etc. Tal lei se encontra em vigor na atualidade tendo sido acompanhada por outras leis como, por exemplo, a Lei 9.610/98 que leciona sobre direitos autorais. Percebe-se, que como na história mundial, no sec. XX. o Brasil alargou o conceito de propriedade intelectual tornando o mesmo mais abrangente, englobando propriedade industrial e autoral como fatores que se somados chegam à propriedade intelectual.

A Lei 9.729/96 traz em seu contexto diversas influências, o que gerou uma certa incompatibilidade de seu texto com o ordenamento jurídico brasileiro. Sobre esse assunto se tem a seguinte lição:

O texto enfim editado tem, marcadamente, o sinal do impacto desses interesses econômicos e políticos. Como comentamos em cada seção específica, o Código de Propriedade Industrial de 1996, um Código que se envergonha de seu título, cabe mal no contexto constitucional brasileiro, e necessita de interpretação vigorosa de que se lhe imponha alguma compatibilidade com a regra básica. (BARBOSA, 2015. pg. 32)

Como é perceptível na lição acima exposta pode se perceber que as influências dos interesses políticos e econômicos nacionais e internacionais que incidiram sobre a Lei 7.729/96 causou um estranhamento entre essa e o ordenamento jurídico brasileiro, principalmente no que tange à Constituição Federal de 1988. O Brasil, no decorrer dos anos, 
tem figurado em diversas disputas que versam sobre propriedade intelectual, as disputas mais recorrentes giram em torno do direito às patentes e suas licenças compulsórias.

Nesse diapasão, notória se faz as implicações internacionais existentes na lei brasileira sobre propriedade intelectual. Tais implicações merecem identificação e reflexão por impactarem das mais diversas formas o ordenamento jurídico brasileiro. O direito de propriedade intelectual internacional se traduz como um ramo extramente consolidado e de muita importância para o desenvolvimento do mercado internacional, motivo, pelo qual, passa a se verificar as implicações do mesmo no direito brasileiro.

\section{O DIREITO DE PROPRIEADE INTELECTUAL INTERNACIONAL E SUAS IMPLICAÇÕES NO DIREITO BRASILEIRO}

A internacionalização do direito da propriedade intelectual tem seu início nos primórdios do desenvolvimento do assunto, ou seja, as Convenções de Berna e Paris já apresentavam indicativos da necessidade de uma uniformização sobre o tema a nível internacional objetivando amenizar os conflitos inerentes dos direitos industriais e autorais. Com o crescente desenvolvimento do mercado e o aumento frenético da demanda por tecnologia mais latente se tornou a necessidade de ter um conjunto de regras que regulassem de forma equânime os direitos de propriedade intelectual.

O surgimento da OMPI e seu ajustamento com a ONU denotou, ainda mais, o caráter internacionalista do direito de propriedade intelectual que passou a ser visto de forma bifurcada abrangendo os direitos autorias e os direitos da propriedade industrial. $\mathrm{O}$ surgimento dos mais diversos tratados, tais como GATT e TRIPS, trouxeram grande mobilização da comunidade internacional, bem como uma enorme aderência.

$\mathrm{Na}$ atualidade é impossível deixar de reconhecer que os direitos da propriedade intelectual possuem forte conotação internacional, vez que são compreendidos como um conjunto de direitos que envolvem marcas, patentes, invenção, inovação, direitos autorais e nome empresarial, o que faz a propriedade intelectual ser necessariamente de cunho internacional:Se há um sistema de propriedade dos bens intelectuais, ele deve ser, necessariamente, internacional. Este postulado é particularmente claro no que toca à proteção da tecnologia. $\mathrm{O}$ país que concede um monopólio de exploração ao titular de um invento está em desvantagem em relação aos que não o outorgam: seus consumidores sofreriam um preço monopolista, enquanto os demais teriam o benefício da concorrência, além de não necessitarem alocar recursos para a pesquisa e desenvolvimento.

De outro lado, a internacionalização da propriedade da tecnologia tem a vantagem de racionalizar a distribuição física dos centros produtores. Se em determinado país 
a nova tecnologia pode ser melhor explorada com a qualidade da mão-de-obra local, com o acesso mais fácil ao capital financeiro e à matéria-prima, para produzir bens que serão vendidos, com exclusividade, com exclusividade, em todo mundo, o preço e a qualidade serão os melhores possíveis. (BARBOSA, 2015, pg. 588)

O trecho trazido a baila denota exatamente a dinâmica do mercado internacional na atualidade, bem como a busca incansável dos mais diversos países por desenvolvimento. Ocorre que a busca pelo desenvolvimento começou a gerar fortes atritos entre países desenvolvidos e em desenvolvimento o que motivou a criação de tratados para amenizar os conflitos multilaterais e garantir igualdade de competitividade aos países em desenvolvimento.

Torna perceptível que com a evolução do mercado e dos meios de produção a proteção da propriedade intelectual se tornou uma forma de garantir o poder de países desenvolvidos. Dominar tecnologias e meios de produção se tornou sinônimo de poder econômico e monopólio. Os países desenvolvidos passaram a temer que suas ideias, principalmente a propriedade industrial, caíssem no domínio público de forma desmedida fazendo com que países em desenvolvimento se apoderassem de suas criações industriais, aumentassem sua produção e desenvolvimento e se tornassem um concorrente em potencial.

Esse cenário forçou a internacionalização dos direitos da propriedade intelectual de forma brusca, forçando a modificação inclusive das primeiras convenções que versaram sobre o tema, como se extraí do trecho abaixo transcrito:

A primeira Conferência das Nações Unidas para o Comércio e Desenvolvimento (UNCTAD) se reúne em 1964 e o primeiro impacto do tema na comunidade internacional se dá com a criação, em 1965, no GATT, de um capítulo especial para os países em desenvolvimento (assinado em 08/02/65). Surge a chamada Carta do Grupo dos 77 em 1967, numa reunião realizada na Argélia e é cunhada a expressão "Nova Ordem Econômica Internacional" numa resolução da ONU datada de 1974, a partir da qual foi iniciado um programa de ação para sua instauração (Res. 3201 (5 VI) e 3203 (5-VI).

O grande dogma da Nova Ordem era o direito ao exercício da soberania econômica conferindo aos Estados: "Cada Estado detém e exerce livremente uma soberania inteira e permanente sobre todas suas riquezas, recursos naturais e atividades econômicas, inclusive a posse e o direito de utilizar e de delas dispor". Deste direito não teriam tido acesso pleno à soberania econômica - fossem beneficiados pela aplicação dos princípios de não-reciprocidade de tratamento preferencial e de medidas diferenciadas para promover seu próprio desenvolvimento. 
A primeira e - até recentemente - única repercussão que tal movimento teve no campo da Propriedade Intelectual foi a inclusão de capítulo especial também na Revisão de Paris, de 1971, da Convenção de Berna para a proteção do Direito de Autor. Mas, nos anos 60 a 80, o tema estava em ebulição tanto no campo da transferência de tecnologia como na Propriedade Industrial.

No campo do direito da Propriedade Intelectual, tal cânone se expressa numa política voluntarista e reformadora, que implicava a intervenção direta na economia internacional, com vistas a compensar as desigualdades de fato a partir da atribuição de maiores diretos aos Estados fracos e maiores deveres aos Estados fortes. (BARBOSA, 2015, pg. 589-560)

Nesse contexto, o Brasil como um país em desenvolvimento ao criar a Lei 9.279/96 sofreu todos os reflexos das normas internacionais. Acordos como o GATT e o TRIPs influenciaram diretamente a criação da lei brasileira que versa sobre propriedade intelectual, vez que a legislação pátria possui como pano de fundo a busca pelo desenvolvimento interno observando os paradigmas internacionais.

Sobre as implicações internacionais à Lei 9.729/96 Jessen (1992, apud BARBOSA, 2015, pg. 30), leciona:

A partir de 1986, com o início a Rodada do Uruguai do GATT, aquilo que eram sinais de mudança tornaram-se claros marcos das novas posturas dos países desenvolvidos, cristalizando-se, em dezembro de 1991, com o texto de GATTTRIPs ("Trade Related Aspects on Intelectual Property"). Evidentemente, tal iniciativa de trazer ao GATT matérias substanciais da Propriedade Intelectual, anteriormente confinada à Organização Mundial da Propriedade Intelectual, não se fez isoladamente.

Assim é que, no próprio âmbito da OMPI, desde o início da década dos oitenta, vinham sendo impulsionadas certas discussões, como a da proteção jurídica dos programas de computador (encerradas abruptamente por uma conclusão dos trabalhos dos expertos que não se coadunava com o encaminhamento das reuniões até então realizadas) e a proteção jurídica dos "microchips" (em que, tendo-se atingido um texto final de tratado internacional, não se obteve, até o momento, nenhuma providência - e a OMPI não tem se esforçado minimamente nesse sentido para assinatura e adesão).

Ainda na OMPI, foram surgindo outras propostas de mecanismos reguladores, tais como as de tratados de harmonização de patentes, harmonização de marcas, solução de controvérsias, harmonização de "designs" e um protocolo à Convenção de Berna, para direitos autorais e conexos. 
Demais disso, as direções do COCOM foram consideravelmente alteradas nos último anos, sem que os países em desenvolvimento lhe prestassem qualquer atenção.

Já não tão claros, os resultados das negociações bilaterais conduzidas prioritariamente pelos EUA (consideradas por aquele país como bastante mais eficazes que as multilaterais) se mostram diretamente nas iniciativas de alteração das legislações domésticas dos países visados, dos quais o Brasil é apenas um de muitos. $[\ldots]$

Numa análise menos que perfunctória o que se nota é a tentativa dos países desenvolvidos de retornarem a uma situação de mera exportação de produto final objeto da patente (seja a patente fim, intermediária ou de meio) e de bloqueio jurídico e fáctico da informação tecnológica, numa espiral que nos recoloca na mesma vertical do início do século. Em consequência, surgiram proibições como a já mencionada da revisão de Estocolmo da CUP e também conceitos novos, de que se destacam o de discriminação, expresso pela primeira vez em GATT - TRIPs, e o dita "reversão do ônus da prova". [...]

Além da lei $n^{\circ} 8383 / 91$, que alterou as normas de remessa e dubilidade, uma das primeiras mudanças a serem implementadas (apesar de ser a mais recente iniciativa) foi a adesão do Brasil ao texto da revisão do Estocolmo (1967), o qual traz, em seu bojo, a proibição de serem extintos privilégios de patentes não explorados pelo titular sem uma concessão de licença compulsória anterior.(...)

A perda da capacidade de os países selecionarem áreas tecnológicas de como não concessão de privilégios e a recusa de introduzir no PL 824/91 os mecanismos de exceção que o GATT admitiu, a retroação da possibilidade de depósito de patente ("pepiline"), muito mais amplo do que a negociada em GATT-TRIPs, o abando do período de transição admitido em TRIP e uma série de outras escolhas, menos flexíveis para o país, devem ser cuidadosamente vistas, pois demonstram até uma certa relação de divergência entre os níveis multi e bilaterais.

Também a questão do segredo da indústria, regulado de maneira pífia no PL 824/91, e a introdução da matéria no GATT, bem como sua transformação, ao longo das negociações, até o conceito de "undisclosed information" (que, aliás, tem passado despercebido), é do mais alto interesse para a aquisição de conhecimento tecnológico e para a produção de bens que utilizem certas inovações tecnológicas, especialmente nas áreas de fármacos e alimentos.

A imposição de certos caminhos judiciais, inclusive com aspectos inadmissíveis no nosso direito ( de que o dispositivo sobre a pseudo reversão de ônus da prova é exemplo) que aparecem em GATT - TRIPs e na Harmonização de Patentes (em contraste aos insípidos dispositivos constantes da PL), a determinação da proteçãodas bases de dados, a possibilidade de limitação da circulação de 
O trecho acima exposto denota qual a essência da Lei 9.729/96 esclarecendo que tal diploma se faz um somatório entre os interesses internos do Brasil e sua perfeita sincronia com os interesses internacionais. Os dispositivos componentes da lei de propriedade intelectual brasileira ou lei da propriedade industrial denotam muito mais elementos favoráveis para a nação do que componentes que denotam a preocupação do Brasil com os direitos da propriedade intelectual em âmbito internacional.

A Lei 9.279/96 é composta por 243 (duzentos e quarenta e três) artigos que regulam as obrigações relativas à propriedade industrial. O texto legal estipula direito e deveres inerentes da propriedade intelectual e que são advindos da necessidade da indústria. $\mathrm{O}$ ponto da lei que mais coloca em foco o Brasil internacionalmente é a regulamentação do direito à patente. A lei estabelece todos os requisitos necessários para se patentear uma invenção, inclusive, regula os direitos do Brasil em deixar de respeitar uma patente estrangeira por meio da invocação da medida compulsória.

O uso da medida compulsória pelo Brasil colou o país ao centro do palco de alguns conflitos multilaterais, a disputa entre Brasil e Estados Unidos - no caso dos medicamentos contra o vírus HIV - teve forte repercussão internacional pelo fato do governo norte americano afirmar o uso indevido da medida compulsória. O Brasil recorrentemente vem sendo acusado por não respeitar os direitos da propriedade intelectual internacionalmente, o que denota que a legislação pátria tentou conciliar os interesses internacionais e nacionais.

A criação e os direitos emanados de uma patente geram conflitos de peso entre os países, vez que uma patente pode ser vista como um direito de domínio por parte de um país desenvolvido em face de um em desenvolvimento. A linha que separa o direito de usar do direito de fazer se faz extremamente tênue, o que traz diversas implicações ao direito Brasileiro. O caso Monsanto que será tratado no presente trabalho se faz um reflexo atual das implicações trazidas ao direito brasileiro por força do direito da propriedade intelectual internacional e permite afirmar que as maiores implicações no direito brasileiro podem ser diagnosticadas em conflitos que envolvem o direito ao uso das patentes.

Para avaliar tais implicações e entender seus reflexos é preciso entender todos os detalhes que constroem o direito à patente e todos os efeitos trazidos pelo mesmo. Nesse sentido é preciso compreender o que sustenta o conflito existente entre o direito de usar e o direito de fazer, compreendendo de fato o que é uma patente e por que a mesma se faz objeto de tantas implicações e disputa entre países. 


\section{DO DIREITO DE USAR AO DIREITO DE FAZER: PATENTES E SUAS IMPLICAÇÕES LEGAIS}

A proteção dos direitos da propriedade intelectual tem o fito de resolver um grande dilema que circula entre o direito de usar e o direito de fazer: evitar o uso indiscriminado de uma tecnologia como se fosse parte do domínio público. A criação de tecnologia se tornou o troféu de grandes países, que tentam proteger a todo custo suas criações que visam aprimorar a produção e a circulação do mercado. Por outro lado, os países que não dominam a produção da tecnologia e precisam dela para se desenvolverem buscam de toda forma ultrapassar a barreira protetora e ter acesso as criações protegidas.

A patente, vista como um direito de proteger uma ideia do domínio público indiscriminado, sobre esse contexto dúbio entre países desenvolvidos e países em desenvolvimento, pode ser analisada de duas óticas distintas. Para quem detém grande poder inventivo, pode ser vista como o direito de fazer e para quem não detém esse direito pode ser vista como o direito de usar.

As patentes ocupam lugar principal no cenário internacional no que tange as disputas multilaterais. São muitas as discussões acerca do abuso do direito de patente versus o desrespeito do mesmo. Para se compreender todas as implicações legais da patente é necessário primeiramente entender o seu conceito, que é definido da seguinte forma:

\footnotetext{
Uma patente, na sua formulação clássica, é um direito, conferido pelo Estado, que dá ao seu titular a exclusividade da exploração de uma tecnologia. Como contrapartida pelo acesso do público ao conhecimento dos pontos essenciais do invento, a lei dá ao titular da patente um direito limitado no tempo, no pressuposto de que é socialmente mais produtiva em tais condições a troca da exclusividade de fato (a do segredo da tecnologia) pela exclusividade temporária de direito. (BARBOSA, 2015. pg. 1099)
}

Vista como um direito reconhecido pelo Estado, uma patente para ser solicitada e declarada enseja a observância de uma série de dispositivos legais para sua concessão, validação e duração. No Brasil toda a regulação do instituto em comento encontra respaldo na Lei 9.279/96 que é dividida da seguinte forma: titularidade, patentiabilidade, prioridade, o pedido de patente e seu procedimento, o exame do pedido de patente, concessão de uma patente, vigência, efeitos da concessão e nulidade de uma patente.

A titularidade é apresentada no Título I, Capítulo I da Lei 9.279/96 e definida no art. 
$6^{\circ}$ exatamente como quem possui o direito de solicitar ao estado o reconhecimento de exclusividade sobre sua criação. Sendo assim, a titularidade nada mais é do que o reconhecimento da legitimidade do inventor em ter sua criação protegida do usoindiscriminado pelo domínio público. $\mathrm{O}$ artigo $6^{\circ}$ do Código de Propriedade Industrial (CPI) cria o tipo de quem pode requer a patente e o que aquele que pede recebe com sua concessão. O sujeito objeto da norma é o autor de invenção ou modelo de utilidade e ao ter deferido o seu pedido terá reconhecido pelo Estado sua propriedade sobre sua invenção podendo gozar dessa em conformidade com a lei.

Contudo a possibilidade de requerimento do reconhecimento do direito de propriedade sobre uma invenção ou modelo de utilidade requer a observação de três requisitos básicos para sua efetivação. Tais requesitos exigidos são denominados pela lei de propriedade intelectual como patentiabilidade, ou seja, é a possibilidade do invento ou modelo de utilidade ser patenteado. A Lei de Propriedade Intelectual brasileira traz, também, em seu artigo 16, um requisito que pode ser considerado como um incidente na garantia do direito à patente. Tal requisito é um manifesto direto do direito internacional de propriedade intelectual e é denominado de prioridade.

A prioridade recai diretamente sobre o pedido de patente de país que mantenha acordo com o Brasil. Sendo assim, se depositado o pedido de patente sobre alguma invenção ou modelo de utilidade em um país que possui acordo com o Brasil tal pedido possui prioridade, vez que o país depositante tem o direito de proteção do invento em todos os países signatários do acordo. Ressalta-se que a prioridade é um reflexo do princípio do tratamento nacional criado na Convença de Paris.

Após a identificação do sujeito de direito e dos requisitos estabelecidos para que se possa invocar a proteção do Estado a Lei 9.279/96 traz o procedimento necessário para se depositar formalmente o pedido e ter o ato estatal solene que confere proteção ao inventor. Nessa toada, pode se considerar que o reconhecimento estatal de uma patente requer uma fase meramente material, onde seja demonstrado todos os requisitos do requerente para invocar tal direito e uma fase meramente procedimental onde o Estado por meio de seus órgãos responsáveis irá certificar todas as alegações e validar tal pedido aplicando sobre ele os efeitos de uma patente.

Todos esses argumentos trazidos pela lei de propriedade intelectual corroboram para que a doutrina classifique os tipos de patentes existentes, são eles segundo Barbosa: 
Quanto ao objeto podem ser de processo, ou de produto, etc., conforme a natureza da solução técnica aportada.

Quanto à finalidade, podem ser patentes de invenção, modelos de utilidade, certificado de invenção etc., ou - como lembra CUP Art. $1^{\circ}(4)$-, patentes deimportação, patentes de aperfeiçoamento, patentes e certificados de adição, etc. (BARBOSA, 2015,pg. 1267)

Da classificação dos tipos de patentes, da observação do sujeito de direito e dos efeitos da patente, pode se dizer que a concessão de uma patente se faz um privilégio concedido ao autor de uma ideia. Tal privilégio é iluminado por questões constitucionais e se perfaz em um perfeito direito à propriedade que consecutivamente deve observar seu valor social. O valor social de uma patente vista como propriedade se faz de extrema importância pelo fato de objetivar evitar o abuso por parte do detentor do privilégio a ele concedido. A discussão acerca do abuso no uso da patente gera as mais calorosas discussões, principalmente por encontrar na medida compulsória ("quebra de patente") um potencial limitador.

A propriedade intelectual encontra-se situada em meio ao progresso e a competitividade. Como se percebe da análise histórica do desenvolvimento dos direitos de propriedade intelectual, todos os países reclamam para si o direito de ter resguardado aquilo que foi pensado e executado com o fim último de desenvolver sua nação. $\mathrm{O}$ rol de direitos que protege a propriedade intelectual é amplo, mas é a figura da patente que recorrentemente se encontra em ênfase.

Entendida como um privilégio estatal, não só pelo Brasil, mas, também, ao entorno do mundo, a patente é um bem incorpóreo que carrega em si o estigma de ser uma propriedade daquele que prova ao Estado ser sujeito desse direito. Sendo assim, vista como uma propriedade pode ser usada da forma que seu detentor bem entender. Porém, a patente vai além de uma aquisição proprietária, uma patente possui um contexto social, o que lhe concede um valor social e limita o seu uso.

Barbosa (2015) ensina que uma patente vai além de uma propriedade por ter o fito de incentivar uma pesquisa e alimentar o progresso e o desenvolvimento de uma nação. A patente possui uma forte carga social, uma vez que é contextualizada como a proteção dos elementos que movimentam e transformam uma sociedade, sendo o principal deles o conhecimento. No caso do Brasil a Constituição Federal estabelece em seu artigo $3^{\circ}$, inciso III, o dever do Estado de promover o desenvolvimento nacional. Tal desenvolvimento tem como um de seus pilares de sustentação a propriedade intelectual que vem regulada na Carta 
Magna no artigo $5^{\circ}$, inciso XXIX, que expressa que o direito de propriedade intelectual servirá, por mais que seja um privilégio, ao interesse social e ao desenvolvimento tecnológico.

Nesse passo, o valor social de uma patente é o limite que o estado concessor dá ao seu possuidor, vez que ressalta ao mesmo que por mais que ele seja detentor de tal privilégioele deverá obedecer aos interesses nacionais, quando invocados em nome da necessidade pública e do desenvolvimento. Sobre esse enfoque leciona a melhor doutrina nacional sobre o tema:

Segundo nosso sistema legal, o nosso sistema constitucional, a propriedade intelectual tem um fim. Ela não é um valor em si próprio. Ela não está protegida simplesmente como uma propriedade. Ela é uma propriedade que serve para um fim determinado. E o fím que lá está indicado é o de propiciar o desenvolvimento social, tecnológico e econômico do país, do Brasil, não da humanidade, nem da comunidade dos povos e, seguramente, não dos titulares das patentes. (BARBOSA, 2015,pg. 1773)

Percebe-se, então, que o valor social de uma patente tem como conceito o seu fim e não o seu status de privilégio e propriedade. É nesse aspecto que o Brasil vem se justificando no decorrer dos anos nos conflitos multilaterais que envolvem o uso da medida compulsória pelo país. Em um posicionamento de dominação em face das grandes potências tecnológicas, o Brasil na busca pelo desenvolvimento interno e por equidade na disputa comercial invoca o que dispõe artigo 68 da Lei 9.279/96, conhecido como "quebra" de patente.

A "quebra" de uma patente é na verdade o uso de um direito previsto na legislação brasileira e denominado de licença compulsória. O artigo 68 da lei de propriedade intelectual leciona que sempre que for violado o valor social de uma patente poderá ser invocado o direito de desconsideração da mesma por meio de uma licença compulsória. Sendo assim, a licença compulsória se faz uma linha tênue entre o uso e o abuso de uma patente.

Recentemente tornou-se fato público e notório a discussão entre agricultores brasileiros e uma empresa norte americana acerca da negativa por parte dos sojicultores em pagar royalties de tecnologia patenteada pela Monsanto. A discussão que permeou por todas as casa do judiciário brasileiro se faz um perfeito exemplo da difícil determinação da interface existente entre abuso e uso de uma patente. Com intuito de aplicar toda a teoria explanada será abordado em forma de caso concreto a disputa judicial entre Brasil e a empresa norte americana objetivando alcançar uma reflexão atual sobre o tema.

5 BRASIL E O CASO MONSANTO: UMA REFLEXÃO SOBRE A INTERFACE ENTRE O USO E O ABUSO DO DIREITO À PATENTE 
O artigo 78 da Lei 9.279/96 estabelece em seu texto legal um prazo de vigência para o gozo do direito à patente, ou seja, todo aquele que requer e tem acolhido o direito de exercer o privilégio sobre determinada invenção o tem por um prazo determinado. A lei prevê outras hipóteses para a extinção de uma patente, mas para o caso concreto que será analisado, éimportante frisar no que leciona o inciso I, do artigo 78, da Lei 9.279/96: expiração do prazo de vigência de uma patente.

A vigência de uma patente é exatamente o divisor existente entre a exclusividade e o domínio público. Uma vez findo o privilégio o bem imaterial protegido pela patente caí em domínio público e pode ser usado indistintamente sem ter que observar nenhum direto de propriedade intelectual. Vista como um limitador de um direito, a vigência de uma patente possui o escopo de atender a finalidade social da mesma, uma vez que conceder um privilégio eterno deixa de reconhecer o direito ao uso e passa a se efetivar o direito ao abuso.

Nesse contexto entre finalidade e vigência de patentes é que em 2009 diversos produtores de soja deram inicio a uma demanda judicial, no Rio Grande do Sul, contra a multinacional norte americana Monsanto. Ressalta-se que produtores do Mato Grosso, também, demandaram contra a Multinacional em Cuiabá alegando cláusulas contratuais abusivas no que tange a cobrança de royalties sobre o uso da tecnologia criada pela empresa no cultivo de soja.

Para se refletir acerca do caso, em especifico sobre o Processo nº 001/1.09.0106915-2, é preciso trazer a baila um dos tipos de patentes classificados na lei brasileira, que é a chamada pipeline e vem descrita no artigo 230 da Lei 9.279/96. Sobre a pipeline leciona Barbosa:

O CPI/96 introduziu um sistema temporário, destinado a corrigir, em parte, a falta de patentes para produtos químicos, e processos e produtos de fins farmacêuticos e alimentares na legislação anterior (arts. 230 e 231 da Lei 9.279/96). Tal instituto, denominado pipeline, visava trazer diretamente ao sistema jurídico brasileiro as patentes solicitadas no exterior ou no Brasil, que aqui não poderiam ser deferidas em face da proibição da lei anterior.

Assim define o instituto um dos mais experientes especialistas:

O termo pepiline - cuja tradução para o português seria tubulação-refere-se, no sentido figurado, aos produtos em fase de desenvolvimento e, portanto, ainda na tubulação que liga a bancada de pesquisa e comércio. Ou seja, ainda poderão ser protegidos. O pepiline também pode ser chamado de patente de revalidação. (BARBOSA, 2015, pg. 1783) 
Sobre esse prisma a legislação brasileira considera para fins de proteção ao objeto da patente a data do deposito do pedido no exterior, desde que o produto não tenha sido posto no mercado. Tal elucidação se faz de grande valia, vez que irá influenciar no prazo de vinte anos de vigência de um privilégio. Argumentos que serão utilizados no embate entre os sojicultores e Monsanto.Com o crescente mercado da soja no Brasil os sojicultores passaram a utilizar das sementes transgênicas para desenvolver a produção e obter um resultado mais efetivo. A tecnologia da semente transgênica foi produzida pela empresa Monsanto e utilizada pelos agricultores brasileiros para movimentar a agricultura e as empresas alimentícias dos produtos derivados da soja, sendo assim, toda a produção de soja no país restou atrelada ao uso da tecnologia da Monsanto.

Em respeito aos direitos de propriedade intelectual todo e qualquer sojicultor que quisesse se valer da tecnologia conhecida como Roundup-ready (RR) deveria estabelecer contrato com o dono da patente e pagar os royalties devidos para uso da tecnologia patenteada, o que enseja o perfeito respeito do direito ao uso do dono da patente em perfeita consonância com o fim social do direito de propriedade intelectual. Porém, como exposto anteriormente o direito de uso da patente se extingue com o passar do tempo, sendo assim se valer desse direito após sua extinção faz-se uma clara e perfeita demonstração do abuso no uso do direito da propriedade intelectual.

Foi exatamente esse o pilar de sustentação da briga judicial entre Monsanto e os agricultores gaúchos. Aquela alegando o seu direito de extensão sobre a tecnologia RR e aqueles alegando a cobrança indevida de royalties, vez que a tecnologia já havia caído em domínio público não havendo que se falar em privilégio advindo do direito de exclusividade. Inconformados com a proibição do cultivar e da comercialização do produto os sojicultores ajuizaram processo judicial em face da Monsanto requerendo o reconhecimento judicial do abuso do exercício do direito à patente da empresa, bem como a extinção da cobrança dos royalties e a devolução dos valores pagos indevidamente.

Em primeiro grau ocorreu o deferimento do pedido dos sojicultores sendo reconhecida a extinção do direito à exclusividade e, portanto o reconhecimento de que a tecnologia RR havia caído em domínio público. A Monsanto, inconformada, apresentou recurso da decisão de primeiro grau e a $5^{\text {a }}$ Câmara Cível do Tribunal de Justiça do Rio Grande do Sul julgou procedente o recurso da empresa sobre o seguinte argumento:

APELAÇÃO CÍVEL. AÇÃo COLETIVA. DIREITO DE PROPRIEDADE
INTELECTUAL. SOJA TRANSGÊNICA. LEI DE PATENTES E LEI DE 


\section{PROTEÇÃO DE CULTIVARES. RAZÕES DE AGRAVOS RETIDOS AFASTADAS E PRELIMINARES SUPERADAS.}

Suficiência do laudo pericial e ausência de nulidade da prova a afastar o acolhimento das razões dos agravos retidos. Preliminares superadas por julgamento no STJ. Afastamento da disciplina normativa do Código de Defesa do Consumidor, não aplicada ao caso em discussão nos autos. No mérito, ainda que a Lei de patentes não permita a proteção decorrente de patentes para todo ou partes dos seres vivos, houveexpressa exclusão desta proibição em relação aos microorganismos transgênicos (artigo 18, inciso III, da lei de patentes), justamente porque resultantes de um produto de intervenção cultural, por meio de invento. Possível à extensão dos efeitos de propriedade intelectual sobre microorganismos transgênicos desde que atendam os critérios próprios à situação jurídica de patenteabilidade - no caso, a novidade, a atividade inventiva e a aplicabilidade à atividade industrial. Circunstancia expressamente reconhecida, por certificados próprios, em relação ao produto ora discutido em juízo. Não há como excluir dos efeitos de proteção desta o produto do objeto de patente, por forca da proteção conferida pelo artigo 42 da Lei 9.279/96. A doutrina na interpretação mais correta da lei de patentes acerca dos casos de propriedade intelectual esclarece que o artigo 42, por meio de seus incisos, protege tanto o produto que é objeto direto da patente, como de processo ou o produto obtido diretamente pelo processo, caso seja este patenteado. Descabe excluiser o direito de patentes sobre o produto de uma intervenção humana por técnica de transgenia - e que abranja todas as características próprias à proteção inclusive quando isto ocorra sobre a cultivar. $\mathrm{E}$ isto, porque ISSN ELETRÔNICO 2316-8080

APONTAMENTOS SOBRE A COBRANÇA DE ROYALTIES DA SOJA RR1 E OUTRAS QUESTÕES EMBLEMÁTICAS EM PROPRIEDADE INTELECTUAL

18 PIDCC, Aracaju, Ano III, Edição n ${ }^{\circ}$ 07/2014, p.14 a 49 Out/2014 | www.pidcc.com.br

ambas as leis mencionadas são omissas na hipótese de sobreposição de situações. Quando uma variedade é desenvolvida pela técnica de transgenia - podendo, portanto, receber a proteção da lei de patentes - e sofre, posteriormente, uma melhora por via biológica, recebendo o certificado de cultivares, em tese, tem-se situação de duplicidade de proteção, algo que estaria vedado pelas disposições da UPOV referente à Convenção de 1978. Tal, conflito, para a doutrina mais recente, enquanto inexistente uma definição legal específica, poderia sofrer solução suficiente por meio do instituto da patente dependente previsto na lei de patentes. Não se trata, portanto, de hipótese de aplicação de lei mais especifica para a resolução do conflito de regras. Aqui se têm leis que disciplinam objetos de tutela diversos. A própria exposição de motivos da cartilha elaborada a lei 9.456/97 deixa clara tal situação quando justifica a criação da lei de proteção de cultivares como 
mecanismo distinto de proteção a propriedade intelectual. Não há como fazer subsistir o argumento de que o licenciamento concedido para a pesquisa sobre o produto e para o desenvolvimento de técnica de aperfeiçoamento afaste o direito originário sobre patentes. $\mathrm{O}$ que pode o titular de patente celebrar contrato de licença para exploração e investir o licenciado nos poderes para agir em defesa da patente (art. 61 da lei de patentes). Tal não afasta os direitos do exercício desta titularidade, seja pelo proprietário do invento, seja pelo licenciado, ressalvada apenas a hipótese de analise do aperfeiçoamento introduzido em patente licenciada (art. 63 da lei de patentes). $\mathrm{O}$ debate proposto é referente ao produto da soja transgênica, para a qual é identificada a situação de proteção específica e comprovada - ao menos até31.08.2010 - por meio de carta patente. Não há, portanto, como se pretender a aplicação de disposições normativas da lei de proteção de cultivares para o caso em comento, na medida em que diversa é a proteção jurídica identificada. Reconhece-se a causa legitima á cobrança - a descaracterizar hipótese de ilicitude para fins do art.

187 do CC brasileiro - por força da aplicação da lei de patentes na hipótese, não afastada a cobrança por situação diversa de proteção do produto pela lei de cultivares, como na hipótese das exceções do art. 10 da lei referida. Com relação ao percentual de royalties estabelecido, a desproporção é apontada ainda na inicial, por meio de pedido alternativo no sentido de que "seja judicialmente estabelecido percentual não abusivo para adequadamente indenizar as demandadas, em índice que variam entre $0,06 \%$ a $0,10 \%$ sobre o valor da soja transgênica comercializada, preferindo o menor. Neste ponto, há que se observar os limites estabelecidos em Lei e mesmo a partir de acordos mais amplos, realizados entre os envolvidos, por meio de suas entidades representativas. Não há que se falar em abusividade quando negociados entre entidades representantes de ambas as partes royalties em percentual $(2 \%)$ proporcional à prática de mercado internacional, sem que demonstrada efetiva abusividade de cobrança. Sucumbência invertida e honorários advocatícios redimensionados em concreto. À UNANIMIDADE, DESACOLHERAM OS AGRAVOS RETIDOS E AFASTARAM AS PRELIMINARES. NO MÉRITO, POR MAIORIA, DERAM PROVIMENTO AO RECURSO, VENCIDO O DESEMBARGADOR JORGE LUIZ LOPES DO CANTO. (RIO GRANDE DO SUL. Tribunal de Justiça. Apelação Cível n. 70049447253. Ação Coletiva. Processo n. 2011/0037199-1. Disponível em:http://www.migalhas.com.br/arquivos/2014/9/art20140925-06.pdf. Acesso: 01/08/2015)

A decisão do Tribunal Gaúcho deixou de observar que a patente concedida à Monsanto havia sido declarada extinta desde o ano 2010, já estando a tecnologia inserida no domínio público. O provimento do Recurso da empresa se fez em uma flagrante violação ao 
que dispõe o artigo 78 da Lei 9.279/96, bem como referendou o abuso do uso da patente por parte da empresa que é conhecida mundialmente por deter o monopólio na área da agricultura.

Tal decisão teve reflexos concretos na realidade comercial brasileira, vez que a grande parte dos produtores se valiam da tecnologia da RR para o cultiva soja. Percebe-se que a decisão transcrita lecionou sobre as patentes como se as mesmas fossem um fim em si mesmo retirando todo o valor social que paira sobre elas. Ao ter tal tipo de leitura restou clara a interface entre uso e abuso do direito de propriedade, pois se vista unicamente como um fim em si mesmo aquela atenderá única e exclusivamente ao abuso, vez que irá ignorar a limitação do uso.

A manutenção da legalidade da cobrança dos royalties pela Monsanto foi uma oficialização à uma possibilidade ilegal de extensão do direito de exclusividade e foi uma outorga jurídica para o exercício do direito à patente de forma abusiva. Os sojicultores recorreram da decisão do Tribunal Gaúcho levando o caso ao Superior Tribunal de Justiça. Em sua defesa a Monsanto alegou que não há que se falar na negativa da cobrança, vez que o prazo de vigência deveria contar à partir do depósito da patente em solo nacional e não à partir do deposito em solo estrangeiro. Totalmente sem razão se fez tal alegação, vez que por se tratar a tecnologia RR de uma patente pipeline deveria seguir o que leciona o artigo 230 do CPI, ou seja, a vigência começa a contar à partir do depósito no estrangeiro e obedecerá o prazo de vinte anos em solo brasileiro.

Rebatendo tal possibilidade a Monsanto alegou que deveria ser suspenso o julgamento por estar em curso no STF o julgamento de Ação Direta de Inconstitucionalidade dos artigos 230 e 231 da Lei 9.279/96. O STJ em 2013 reconheceu a ilegalidade na cobrança feita pela Monsanto reconhecendo o fim do privilégio concedido à empresa a título da exclusividade. Restou declarado que a tecnologia caiu em domínio público em 31/08/210 e que, portanto não mais se poderia cobrar royalties dos sojicultores. Sendo assim, a justiça brasileira reconheceu o domínio público da tecnologia da soja RR inviabilizando o exercício do direito à patente pela Monsanto. Ainda, inconformada, a Monsanto apresentou embargos de divergência ao STJ alegando que no caso do Recurso Especial no 411.529-SP ocorreu entendimento contrário. A decisão favorável aos sojicultores é mantida com efeito erga omnes e os Embargos de Divergência ainda não foram julgados.

A análise do caso deixa clara a importância de se determinar a interface entre uso e abuso do direito à patente, vez que essa interface nada mais é que a garantia do valor social que reveste os direitos de propriedade intelectual. Como exposto no decorrer do presente 
escrito, os direitos de propriedade intelectual possuem caráter internacional o que determina a incidência de princípios aplicados internacionalmente à propriedade intelectual. A decisão do STJ em considerar extinto o direito de privilégio da Monsanto não violou nenhum dos princípios internacionais que regem a disciplina por estar em perfeita consonância com a lei de propriedade intelectual brasileira, que por sinal respeita os preceitos internacionais.

A interface que compõe o direito à patente nada mais é que as medidas que devem ser tomadas pelos Estados para se evitar que o direito à patente se torne um mecanismo anticoncorrência e de abuso por parte dos detentores de tais privilégios, a premissa de que a patente não é um fim em si mesma é a interface entre o uso e o abuso desse direito e deve ser contemplada a fim de se evitar a invocação indevida dos direitos de propriedade intelectual.

\section{CONCLUSÃO}

A propriedade intelectual se faz uma substância de crucial importância para a movimentação e desenvolvimento de uma nação. A luta existente entre países desenvolvidos e países em desenvolvimento não pode se valer dos privilégios trazidos pelo direito de exclusividade a fim de se fazer liberdade para uns e algemas para outros. O caso da disputa entre os sojicultores e a Monsanto demonstra exatamente a importância de se delimitar o uso do direito da propriedade intelectual. Ser detentor do direito à patente é uma forma de se reconhecer e até mesmo incentivar a ciência e o desenvolvimento, mas a detenção desse direito não pode ser utilizada como uma arma em detrimento dos que não o possuem.

O uso desmedido de um privilégio transcende as margens do direito se fazendo uma perfeita violação de um direito alheio, principalmente quando se trata de direitos que envolvem a propriedade intelectual. Entendida na contemporaneidade como o ramo do direito que reconhece o bem incorpóreo e o protege a fim de propagar a pesquisa e o desenvolvimento social, a propriedade intelectual deve observar uma medida justa de aplicação.

A reflexão sobre a interface existente entre o uso e o abuso do direito à patente demonstra que o próprio judiciário brasileiro entra em conflito quando o assunto é a limitação de um direto subjetivo em detrimento a um direito coletivo, o que denota a relevância de se estudar e sempre refletir sobre o assunto. O caso Monsanto deve ser analisado das mais diversas posições possíveis, pois a conclusão apresentada pelo mesmo é um ponto à favor da maturidade do pensamento jurídico acerca da propriedade intelectual e em especial sobre o uso e abuso do direito à patente. 
Nesse diapasão, ao concluir que a decisão do STJ está em perfeito compasso com os ditames da propriedade intelectual internacional e que fez jus ao que leciona a legislação pátria sobre o tema pode se afirmar que em meio às tantas discussões sobre o tema o Brasil tem demonstrado certa evolução e ganhado cada vez mais maturidade acerca da matéria. $\mathrm{O}$ choque entre o direito de fazer e o direito de usar sempre irá ocorrer, vez que cada nação apresenta interesses diferenciados, mas a interface entre o uso e o abuso do direito da propriedade intelectual deve ser bem delimitada com o escopo de neutralizar tal duelo de forma justa e acima de tudo fazendo valer os direito da propriedade intelectual.

\section{REFERÊNCIAS}

ASSAFIM, João Marcelo de Lima. A Transferência de Tecnologia no Brasil: aspectos contratuais e concorrências da propriedade industrial. Rio de Janeiro: Lúmen Jurís, 2005.

BARBOSA, Denis Borges. Tratado da Propriedade Intelectual. Rio de Janeiro: Lúmen Jurís, 2013.

BARBOSA, Denis Borges Barbosa. Tratado da Propriedade Intelectual/Patentes. Rio de janeiro: Lumen Jurís, 2014.

BRAGA, Samantha Bancroft Viana. Noções Sobre o Abuso do Direito de Propriedade Intelectual $\mathrm{e}$ da Doutrina do Patente Misuse.

Disponível em:http://www.abpi.org.br/biblioteca. Acesso em: 09 de agosto de 2015.

BRANT, Cássio Augusto Barros. Lições Preliminares de Propriedade Intelectual. Belo Horizonte: Edição do Autor, 2012.

CHAVES, Antônio. Evolução da propriedade intelectual no Brasil. São Paulo: Revista dos Tribunais, 1992.

DINIZ, Davi Monteiro Diniz. Propriedade Industrial e Segredo em Comércio. Belo Horizonte: Del Rey, 2003.

GUSTIN, Miracy Barbosa de sousa; DIAS, Maria Tereza. (Re)pensando a Pesquisa Jurídica. Belo Horizonte, 2015.

HAMMES, Bruno Jorge. O Direito de Propriedade Intelectual. São Paulo: Unisinos, 2002.

LEOPOLDINO DA FONSECA, João Bosco. Direito Econômico. Rio de janeiro: orense, 1988. 
MALLMANN, Querino. Fundamentos Jurídicos-Filósoficos Sobre a Origem e Titularidade das Patentes e Invenções. Disponível em: http://pidcc.com.br/images/15062014. Acesso em: 05 de agosto de 2015.

MELO, Renato Dolabella. Patentes e Desenhos Industriais: instrumentos legais para coibir o abuso. Belo Horizonte: Arraes Editoras, 2011.

MARTINS, Pedro Baptista. O Abuso de Direito e o ato Ilícito. Rio de Janeiro: Forense, 2002 .

PINTO, Ana Paula Gomes. Revalidação de Patentes. Rio de Janeiro: Lumen Juris, 2014.

PLAZA, Charlene Maria C. Das Patentes aos Royalties - $O$ caso da soja transgênica da Monsanto. Disponível em: http://pidcc.com.br/artigos/032013/edicao0301. Acesso em: 08 de agosto de 2015.

SOUZA, Rebeca Hennermman Vergara. Sequestraram a Propriedade Intelectual: uma agenda para desenvolvimento na Organização Mundial da Propriedade Intelectual. 2009. 28876. Dissertação (Mestrado em Sociologia) - Faculdade de Ciências Humanas, Universidade Federal do Rio Grande do Sul. Disponível em: http://hdl.handle.net/10183/28876. Acesso em: 07 de julho de 2015.

VIZZOTTO, Alberto. A Função Social das Patentes Sobre Medicamentos. São Paulo: LCTE, 2010. 